\title{
Hydrochloric acid treatment of the well
}

\author{
Shukurov Abror Sharipovich ${ }^{1}$ \\ ${ }^{1}$ Master, Karshi Engineering and Economics Institute \\ Email:shukurov_a@umail.uz.
}

\begin{abstract}
This article is about salt chemical treatment and hot acid treatment of wells

Keywords: rocks, limestone, Dolomite, hydrochloric acid solutions, UFE8, Mg, indicators.
\end{abstract}

\section{INTRODUCTION}

Towards the bottom of the oil well in low-permeability hard rocks the flow will be small regardless of how large the depression is. Such a mountain how much pressure water in the drive wells made of rocks the drive will be too small to accept? In such wells, product flow or acceptance level artificial exposure techniques are used to increase for this increase the number and size of pores, cracks in the rock (porosity) expansion, as well as paraffin and resins will have to be obtained. According to the description of the impact around the bottom of the well, the following groups are divided into: mechanical, chemical and thermal. Get good results with these methods for this reason, applying these methods over and over again gives good results. The methods of impact around the bottom of the well are selected depending on the conditions of the formation is obtained. From the resin and paraffin that sit on the wall of the porous tubes thermochemical and for refining and reducing the viscosity of oil heat gives good results when chemical methods are used. Kam permeable carbonate (dolomite, limestone) to rock layers acid treatment is available. Mechanical methods - from dense rocks it is best applied in structured productive layers. The hydrochloric acid treatment method for the well was initially limited to carbonate mining. If used in collector deposits of rocks, then it application has expanded.

a) Carbonate rocks and containing carbonate, sandstone processing in order to increase well flow rate in reservoir deposits.

b) In order to increase the capacity of the drive wells acid treatment around the bottom of the well.

c) Processing to dissolve salt layers.

g) Thermo-acid to remove paraffin-resin residues from pores processing

The method of hydrochloric acid treatment of carbonate rocks of hydrochloric acid based on melting. This reaction proceeds as follows.

A) $2 \mathrm{HCl}+\mathrm{CaCO} 3=\mathrm{CaCl} 2+\mathrm{H} 2 \mathrm{O}+\mathrm{CO} 2$ for limestone

B) $4 \mathrm{HCl}+\mathrm{CaMg}(\mathrm{CO} 3) 2$ for dolomite $=\mathrm{SaCl} 2+\mathrm{MgCl} 2+2 \mathrm{H} 2 \mathrm{O}+2 \mathrm{CO} 2$

$\mathrm{The} \mathrm{CaCl} 2$ and $\mathrm{MgCl} 2$ formed as a result of the reaction are well soluble in water and it is easy to get out of the well. At present, acid treatment

The following types are available:

1) Acid baths;

2) Simple acid treatment;

3) Acid treatment under pressure;

4) Thermal chemical and hot acid treatment;

The purpose of the acid bath treatment is to surround the bottom of the well from contaminants (cement or clay shells and corrosion products) cleaning. The method of acid bath is different from other methods in that it is an acid solution is obtained by the thickness of the productive layer, which is not affected by pressure. The method of acid treatment under pressure is different from the usual method under pressure $(200,250,300 \mathrm{kgf} /$ $\mathrm{cm} 2$ ) is being processed. The effect of processing is the concentration of acid, its amount, pressure, temperature, rock description, and so on. With $8-15 \%$ concentrated hydrochloric acid solution around the bottom of the well the processing is efficient. High concentration hydrochloric acid solution affecting the strength of well equipment as a result of treatment with causing them to fail quickly. Reacts with gypsum forms residues in the pores. Low concentration hydrochloric acid solutions to obtain a larger amount of acid solution during processing and makes it difficult to derive the results of the reaction. $1 \mathrm{~m}$ thick acid with a concentration of $8-15 \%$ in a volume of $0.4-$ 
$1.5 \mathrm{~m} 3$ for processing solution is needed. Layered from low-conductivity collectors and low-flow 0.4-0.6 m3 of acid solution is used for well treatment. High $0.8-1 \mathrm{~m} 3$ of acid solution is used for the conductive layers. It is composed of high-permeability rocks and has a high initial flow rate 1-1.5 m3 of acid solution is used for wells. Wells with low formation pressure have 10-12\% hydrochloric acid solution. 12-15\% in high pressure wells gives better results when treated with hydrochloric acid. $8 \%$ acid solution for processing layers composed of carbonated sandstone applied. Hydrochloric acid is used to treat the bottom of the well decomposes equipment. Inhibitors are added to prevent this. Inhibitor Formalin is used as $6 \mathrm{~kg}$ of formalin per ton of acid solution reduces the corrosion activity of the solution by 7-8 times. The most common inhibitor - unicol PB-5 - is a brown liquid corrosion activity is $31-42$ when $0.25-0.5 \%$ of unicol is added times. Unicol is completely soluble in hydrochloric acid, but in water insoluble. Therefore, after the reaction, the acid solution is converted to $\mathrm{CaCl}$ and $\mathrm{MgCl}$ when it rotates, a residue remains from it, which is its shortcoming. So do it a very small amount of $0.1 \%$ is added, which increases the corrosion activity up to 15 times reduces.

In addition to the inhibitors mentioned above, I-I-A and uratropin mixture and UFE8s. Intensifiers to increase the efficiency of processing, i.e. surface active ingredients are added. Surfactants such as OP-10, UFE8, carbosalin $\mathrm{O}$, catapin and catamine When added, the reaction of the acid with carbonates is reduced by a factor of 3. Hydrochloric acid is produced at the plant in high concentrations. This is him It is difficult to apply in the case of water to the desired concentration before use mixed with.

There are 4 types of hydrochloric acid:

a) Synthetic technical hydrochloric acid;

b) Technical hydrochloric acid;

c) Hydrochloric acid prepared from obgas of organic origin

g) Inhibited hydrochloric acid in the plant; The acid solution in the treatment of hydrochloric acid in the well is a central acid at the base or around the well being processed for this

The total additives from the amount of water shown in the table are acetic acid and if necessary, subtract the sum of the amounts of fluoric acid into the measuringt vessel poured. Then calculate the amount of acid in the water according to the instructions put in a bowl over and mix well. Density solution concentration is checked and if water is low - water, if acid is low - acid is added. $\mathrm{BaCl}$ is then added to the solution until it is mixed. The heat in the well is a chemical and hot acid treatment, hot salt acid treatment. Hydrochloric acid in the well and reagents $(\mathrm{Mg}$, etc.) react to release heat, i.e. heating occurs under the influence of an exothermic reaction. Cleaning paraffin and tar from the well to improve oil flow heat is used chemically. Caustic soda in the well to create a high temperature at the bottom of the well, $\mathrm{Mg}$ and others are reduced, react with hydrochloric acid, and heat is released turns out. The following reaction takes place between the acid and $\mathrm{Mg} . \mathrm{Mg}+2 \mathrm{HCl}+\mathrm{H} 2 \mathrm{O}=$ $\mathrm{MgCl} 2+\mathrm{H} 2 \mathrm{O}+\mathrm{H} 2+110.2 \mathrm{kcal} 1$ gram of a molecule ( 24 grams by weight) dissolves in $\mathrm{Mg}$ acid $110.2 \mathrm{kcal}$ of heat is released or 4520 when dissolved in $1 \mathrm{~kg} \mathrm{Mg}$ of hydrochloric acid kcal of heat is released. Concentration of 18.62 liters for complete dissolution of $1 \mathrm{~kg} \mathrm{Mg} \mathrm{A} 15 \%$ hydrochloric acid solution is required. In the experimental method, when $1 \mathrm{~kg}$ of $\mathrm{Mg}$ is completely dissolved in $15 \%$ acid, it is as follows indicators were obtained.

\section{REFERENCES}

1. Mirziyoyev Sh.M. "It simply came to our notice then "Improving our well-being is at the heart of all our efforts." People's Word Newspaper, February 25, 2017, № 41 issue.

2. Irmatov E.K. Project probnoy ekspluatatsii mestorozhdeniya Kruk: Report on NIR / OAO "UzLITIneftgaz"; - Tashkent, 1986.

3. Irmatov E.K. Technological scheme of development of mestorozhdeniya Kruk / OAO UzLITIneftgaz; Tashkent, 1989.

4. Irmatov E.K. Analysis of the development of Kruk / UzbekNIPIneftegaz; Otvetsvenniy ispolnitel Tashkent, 1994.

5. Irmatov E.K. Project development mestorojdeniya Kruk: Report on NIR / OAO UzLITIneftegaz; Otvetstvenniy ispolnitel - Tashkent, 2002 